\title{
Laboreal
}

Volume $8 \mathrm{~N}^{\circ} 1$ | 2012

Género, Atividades e Saúde

\section{Análise de alguns mecanismos de aquisição dos primeiros elementos de uma profissão pelo adolescente}

Análisis de algunos mecanismos de adquisición de los primeros elementos de un oficio en el adolescente

Analysis of some mechanisms the teenager uses to acquire the first elements of a profession

\section{Antoine Léon}

\section{(2) OpenEdition}

\section{Journals}

\section{Edição electrónica}

URL: http://journals.openedition.org/laboreal/7390

DOI: $10.4000 /$ laboreal.7390

ISSN: $1646-5237$

\section{Editora}

Universidade do Porto

\section{Refêrencia eletrónica}

Antoine Léon, «Análise de alguns mecanismos de aquisição dos primeiros elementos de uma

profissão pelo adolescente », Laboreal [Online], Volume $8 \mathrm{~N}^{0} 1$ | 2012, posto online no dia 01 julho 2012, consultado o 24 setembro 2020. URL : http://journals.openedition.org/laboreal/7390 ; DOI : https:// doi.org/10.4000/laboreal.7390

Este documento foi criado de forma automática no dia 24 setembro 2020.

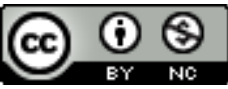

Laboreal está licenciado com uma Licença Creative Commons - Atribuição-NãoComercial 4.0 Internacional. 


\section{Análise de alguns mecanismos de aquisição dos primeiros elementos de uma profissão pelo adolescente}

Análisis de algunos mecanismos de adquisición de los primeros elementos de un oficio en el adolescente

Analysis of some mechanisms the teenager uses to acquire the first elements of a profession

Antoine Léon

\section{REFERÊNCIA}

Artigo original : Léon, A. (1957). Analyse de quelques mécanismes d'acquisition des premiers éléments d'un métier chez l'adolescent. Bulletin du CERP, 2, 183-188.

1 As observações que vão ser apresentadas, resultado de um trabalho realizado em colaboração com M. C. Dacquin, Professor-Adjunto no Centre d'application de l'École normale nationale d'apprentissage de Paris [Centro de aplicação da Escola Normal de Aprendizagem de Paris], enquadram-se no âmbito das preocupações definidas por S. Pacaud no número especial do Journal de Psychologie [jornal de psicologia] dedicado à Psicologia do Trabalho (n. .1 de 1955) :

“ (...) O insucesso de um indivíduo na sua profissão quase nunca reside no facto de que este não aprendeu actos úteis, mas de que não soube livrar-se de actos inadequados. Dito de outra forma, na cadeia de associações que conduzem quer a operações motoras, quer a operações intelectuais e mentais, desencadeiam-se, além das associações seleccionadas pela formação profissional, outras ligações, primeiro fortuitas, depois facilitadas após repetição, que determinam erros profissionais nos executantes... ». 
Qual é o conteúdo desses erros, quais são as condições concretas da formação dessas ligações defeituosas no decorrer da aprendizagem profissional, no caso do adolescente?

4 É a este duplo questionamento, simultaneamente psicológico e pedagógico, que tentaremos fornecer alguns elementos de resposta, estudando alguns mecanismos de aquisição dos rudimentos da profissão de fresador no caso de 25 formandos do segundo ano de um centro público de aprendizagem.

\section{Método de observação e controlo}

Os formandos analisados são aprendizes de 15-16 anos que já fizeram um primeiro ano de rectificação e, no início do segundo ano, um estágio de orientação e de iniciação nas três oficinas de mecânica (rectificação, torneamento, fresagem) antes de serem afectos a uma oficina da sua escolha.

6 A iniciação à fresagem estende-se por um período de uma semana comportando 18 horas de presença efectiva na oficina. Os formandos chegam em grupos de quatro e trabalham em máquinas que se encontram num espaço restrito. Desta forma, é possível proceder não apenas ao estudo dos comportamentos individuais dos aprendizes, como também a comparações de conjunto, fazendo alternar grupos submetidos a meios educativos diferentes.

$7 \quad 1{ }^{\circ}$ Estudo dos comportamentos individuais. $\mathrm{O}$ balanço das dificuldades encontradas $\mathrm{e}$ dos erros cometidos pelos aprendizes durante o estágio de iniciação é feito numa primeira fase do estudo. Os formandos são questionados, quer directamente, frente às máquinas, quer durante um teste oral. Uma primeira hipótese sobre o conteúdo de alguns erros observados pode então ser avançada : o mecanismo em causa parece um processo de generalização precipitado. Numa segunda etapa, situada no início do ano lectivo 1955/1956, são analisados, à luz dessa hipótese, e tendo em conta os meios pedagógicos à disposição do aprendiz, os comportamentos reais adoptados para lidar com as dificuldades encontradas. Os formandos são convidados a explicar e a justificar eles próprios um determinado acto profissional particularmente difícil. Por vezes, são criadas situações problemáticas na própria máquina, a fim de esclarecer mais eficazmente o processo estudado.

$8 \quad 2{ }^{\circ}$ Comparações de conjunto. Para controlar o papel desempenhado por alguns factores educativos na génese dos erros profissionais cometidos, dividimos os formandos em dois grupos submetidos a dispositivos pedagógicos parcialmente diferentes. Enquanto os formandos do grupo de controlo são iniciados à fresagem seguindo um método que poderíamos, condicionalmente, qualificar de global, intuitivo, os do grupo experimental são constantemente convidados a fazer um esforço de análise e de utilização de conhecimentos gerais na fase preparatória do trabalho de máquina propriamente dito.

9 A comparação dos dois grupos efectuou-se com base num teste final que incidiu, numa nova situação, em problemas idênticos aos encontrados durante o estágio. Após o teste, os aprendizes são ainda submetidos a entrevistas individuais durante as quais são aplicadas provas concebidas com base nas principais dificuldades encontradas durante o curso de aprendizagem. 
10 Não vamos aqui analisar todas essas dificuldades. Limitar-nos-emos a algumas observações psicológicas relativas à assimilação das primeiras regras de fresagem.

Dado que não podemos dar exemplos concretos cuja relação exigiria desenvolvimentos tecnológicos, apresentaremos de uma forma elaborada o conteúdo e as condições educativas de alguns erros profissionais cometidos pelos aprendizes fresadores.

\section{Da generalização precipitada à generalização correcta na aquisição das primeiras regras da fresagem}

12 Ao longo das nossas observações, impôs-se progressivamente o seguinte fenómeno: entre as explicações e as instruções orais ou escritas fornecidas pelo Professor-Técnico e as respostas efectivas (verbais ou motoras) do aprendiz, intercala-se uma actividade mais ou menos consciente que consiste, neste último, em generalizar alguns aspectos parciais dessas explicações e instruções ou as ligações que se criam, sem o conhecimento do Professor, durante o próprio trabalho do formando. Analisaremos esse fenómeno e apresentaremos algumas das suas condições.

1.' Alguns aspectos do processo de generalização. Apresentam-se sob diversas formas.

- Por vezes, resultam de uma análise prévia insuficiente e consistem na transposição mecânica de uma situação A para uma situação B, de exigências secundárias, específicas da primeira situação. Assim, a aplicação de uma determinada regra, válida para um determinado exercício, é erradamente alargada a outros exercícios. Essa regra está separada do seu contexto, isto é, do conjunto das exigências da tarefa. Um aprendiz manipula um volante para regular a sua máquina num determinado exercício e continua a utilizar o mesmo volante no exercício seguinte, quando as condições de trabalho mudaram.

- Em outros casos, os processos de generalização resultam de uma análise prévia e apresentam-se como a extrapolação de relações mais ou menos complexas e apreendidas de forma mais ou menos correcta. Assim, os aprendizes extrapolam, em situações novas, relações espácio-temporais apreendidas entre as sucessivas operações de um determinado exercício. A título de exemplo, descobrem determinadas relações de simetria nas posições ocupadas pela ferramenta em sucessivos exercícios. Generalizam relações para determinar a posição da ferramenta num novo exercício.

14 Com frequência, transpõem a ordem das operações efectuadas durante o estágio para a sequência das operações a realizar durante o teste. Por vezes, justificam a existência das relações identificadas invocando o que eles pensam ser as intenções pedagógicas do Professor-Técnico. “No primeiro exercício - declaram em suma - pediram-nos para regular a máquina com este volante ; no segundo exercício, com este ; portanto, para o terceiro exercício, utilizaremos este último volante a fim de conhecermos melhor a máquina ».

Encontramos este fenómeno de interpretação das intenções pedagógicas do professor na forma como os aprendizes utilizam as instruções técnicas que completam o desenho da peça a realizar. Se a presença de instruções específicas de execução dispensam muitas vezes o aluno de todo e qualquer esforço de investigação, levam-no por vezes a estabelecer comparações entre os sucessivos exercícios de uma progressão. Em vez de preparar o seu trabalho em função das exigências específicas da tarefa em causa, 
contentam-se em interpretar certas alterações ocorridas nas condições dessa tarefa, fazendo intervir o que eles julgam ser as intenções pedagógicas do professor.

16 A tomada de consciência dos diferentes tipos de relação que acabam de ser evocados dá lugar à elaboração, pelos próprios formandos, de verdadeiras regras que substituem as instruções dadas. Eficaz em alguns casos, a aplicação dessas "regras" conduz, em outros casos, a soluções erradas.

c) A ilustração mais significativa do processo de generalização estudado é-nos fornecida pela regra individualmente "descoberta" e aplicada por todos os aprendizes observados com vista a proceder à operação mais importante da regulação da máquina, pelo menos, ao nível da iniciação à profissão. Este fenómeno surgiu com tanta insistência, com um tal grau de generalidade, melhor ainda, a regra "descoberta" pelos formandos era expressa de uma forma tão homogénea, que nos incumbe sublinhar determinadas observações que a esta dizem respeito. Essa regra, válida na prática em numerosos casos, apenas reflecte a sequência dos movimentos realmente executados nesses casos (rotação em determinado sentido do volante de regulação da máquina, depois no sentido oposto).

Como explicar que essa regra se substitui à regra ensinada pelo Professor-Técnico ?

19 Se o formando recorre, no seu trabalho, a uma regra simples que resulta da tomada de consciência de ligações motoras que se criam e se reforçam durante a actividade prática, é sem dúvida porque é rejeitado pelo número e pela complexidade das operações intelectuais exigidos pela aplicação dos ensinamentos do Professor nomeadamente a aplicação das leis da composição das forças. Devido à persistência e à solidez dessas ligações, a maioria dos aprendizes, frente a uma tarefa para a qual a regra por estes "descoberta" é manifestamente inaplicável, é incapaz de aplicar a regra demonstrada pelo formador. No entanto, alguns deles resolveram correctamente o problema, alguns minutos antes, através de um esquema.

Assim, a aplicação correcta das regras num trabalho com esquema não garante a sua assimilação pelos formandos. A passagem do exercício intelectual com esquemas resultado de acções educativas "intencionais" exercidas por parte do Professor-Técnico - ao acto propriamente dito não é simples, mecânico. Novos condicionamentos, fruto da actividade do próprio formando, influenciam essa passagem fazendo intervir elementos formadores que poderíamos qualificar de "não intencionais", já que se manifestam sem o conhecimento do formador. Essas duas formas de condicionamento estão mais ou menos bem integradas num mesmo formando.

21 Por vezes, acontece que um aprendiz, depois de ter "repetido" correctamente as regras ensinadas pelo Professor-Técnico, se coloca de seguida, quando se trata de manobrar a máquina, ao nível das pseudo-regras que ele próprio elaborou. Sobre esse aprendiz, poderíamos inverter os termos do aforismo segundo o qual "O homem de hoje pensa como Copérnico e fala como Ptolomeu" quando declara que "o sol nasce ou se põe".

Por vezes, o formando passa facilmente de um modo de explicação para outro, baseando-se quer em elementos conceptuais ou representativos da demonstração do Professor, quer em dados da sua própria experiência, em apreciações que vêm de uma visão global, intuitiva, do acabamento da peça.

À luz dessas observações, um dos principais problemas que se colocam simultaneamente ao psicólogo e ao formador é o de saber se a intervenção de certos factores educativos "intencionais" pode contribuir para melhorar o processo de 
generalização do aprendiz, isto é, definitivamente, para reduzir a importância dos erros profissionais.

Tabela 1

TABELA I

\begin{tabular}{|c|c|c|c|}
\hline \multirow{2}{*}{ Ordem dos grupos } & \multirow{2}{*}{ Grupo } & \multicolumn{2}{|c|}{ Exame de controlo } \\
\hline & & Com esquema (de 0 a 10 ) & Com cálculo (de 0 a 10$)$ \\
\hline 1 & Controlo. & 7 & 9 \\
\hline 2 & Experimental ….................. & 7,8 & 5 \\
\hline 3 & Controlo $\ldots \ldots \ldots$ & 5,4 & 10 \\
\hline 4 & Experimental ........................... & 7,1 & 8 \\
\hline 5 & Controlo... & 6,3 & 8,3 \\
\hline 6 & Experimental ....... & 7,7 & 6,7 \\
\hline 7 & Controlo. & 6,6 & 9,3 \\
\hline
\end{tabular}
conta, por um lado, a discordância dos resultados registados nos dois exercícios, e, por outro lado, a persistência dessa discordância nos resultados calculados, já não globalmente, mas grupo a grupo. Os resultados, classificados por ordem cronológica [1] $\left.{ }^{*}\right)$, obtidos pelos sete grupos que se sucederam no estágio de fresagem encontram-se na tabela I. Para explicar esta série de discordâncias, convém, na nossa opinião, ter em conta as condições específicas nas quais decorreu o estágio para os dois grupos. Na preparação do trabalho, a actividade de investigação e análise era sobretudo desenvolvida pelos formandos do grupo experimental. Estes últimos eram convidados a distinguir - em particular na fase preparatória do trabalho - as diferentes forças que resultavam do contacto da ferramenta com a peça. Esta actividade parece ter melhorado a qualidade do processo de generalização, isto é, em suma, a qualidade das respostas fornecidas pelo formando na situação nova do exame. Com efeito, é legítimo pensarmos que a análise aprofundada de uma situação permite distinguir os aspectos secundários dos aspectos essenciais dessa situação e operar generalizações correctas a partir desses últimos. É então concebida a superioridade relativa do grupo experimental relativamente ao grupo de controlo no exercício com esquema. 

tivo limitado e imediato: relações espácio-temporais elaboradas a partir de indícios visuais ou motores que retiram o seu próprio significado do contexto directo do adolescente com a máquina. Outros estão ligados a um meio educativo mais vasto : 0 aprendiz utiliza mais ou menos correctamente determinados conhecimentos (lei da composição das forças) ensinados pelo professor de ciências. Outros, finalmente, estão associados a toda a experiência escolar do aprendiz: a noção de "progressão" dos exercícios, forjada durante a vida escolar, levam-no a interpretar as intenções pedagógicas actuais do seu Professor-Técnico profissão deveria fazer intervir outros factores, em particular a motivação com todo o seu conjunto de determinações sociais.

As observações psicológicas que acabam de ser apresentadas sobre a assimilação das primeiras regras de fresagem são parcialmente generalizáveis e vão de encontro, por exemplo, às teses formuladas por Ombredane e Faverge na sua mais recente obra dedicada à análise do trabalho. Depois de sublinhar a importância do papel desempenhado pelos sinais (nuances do metal aquecido, indicações do manómetro) na realização dos actos profissionais, esses autores ilustram, através de numerosos 
exemplos, os aspectos que, numa determinada tarefa, "são imprevistos e sujeitos à descoberta do trabalhador".

Ao examinar de perto o mecanismo da orientação profissional ou, mais precisamente, o processo de elaboração da opção profissional pela criança, descobre-se, também aqui, o desenvolvimento de uma actividade "autónoma" que escapa, em certa medida, ao controlo do mestre ao do conselheiro de orientação profissional. Assim, a informação sobre algumas famílias de profissões cria, nos alunos que terminam o ensino primário, uma atitude - muito clara na escolha ou na recusa de uma profissão - que tende a generalizar-se e durante a qual a criança elabora os materiais diversos que provêm do seu meio envolvente, sobretudo da sua família [²].

Se deixarmos o âmbito das profissões e passarmos ao das disciplinas escolares, podemos observar mecanismos intelectuais comparáveis, de certa forma, aos que acabámos de descrever. Assim, J. Levine [3], baseando-se em algumas teses de Wallon, demonstra que a actividade de aquisição " consiste em elaborar uma espécie de duplicado do texto e que esse duplicado, sobreposto ou mesmo substituído em alguns casos aos vestígios directos que a audição vai deixando, constitui a matéria fundamental da memória ». A actividade de identificação das realidades expostas num texto escapa, em grande parte, à influência directa do educador, já que a experiência social extra-escolar da criança tem aqui um peso considerável.

Estas achegas, que mereceriam um desenvolvimento mais longo, contribuem no entanto para explanar o ponto de vista segundo o qual os problemas psicológicos e pedagógicos levantados pela iniciação à profissão não são, na essência, diferentes dos colocados pelo ensino das disciplinas ditas gerais.

Para terminar, gostaríamos, a propósito deste estudo, de evocar um problema mais geral.

39 Os factos que acabam de ser analisados são da alçada da psicologia ou da pedagogia? Parece-nos que das duas disciplinas ao mesmo tempo. Com efeito, dizem respeito não apenas às condições externas da assimilação de um determinado sector de conhecimentos - o ensino profissional - como também aos mecanismos internos dessa assimilação. Será possível falar de confusão entre domínios supostamente distintos ou de degradação da psicologia sob pretexto que as observações têm por objecto a actividade escolar e conduzem a certas aplicações pedagógicas ? Pensamos que não. A diversidade das dependências do facto psíquico legitima tanto a investigação psicopedagógica como a investigação psicofisiológica, a investigação em laboratório ou a relativa à actividade normal - por exemplo, escolar ou profissional - do homem. Por outras palavras, a psicopedagogia, longe de ser uma categoria cómoda imaginada para agrupar fenómenos mal definidos, responde, pelo contrário, à própria natureza de determinados factos de que a psicologia se ocupa.

Mais importantes do que as distinções que nos esforçamos por estabelecer entre campos de actividade que se sobrepõem necessariamente se por isso se confundirem, parecem ser as divergências entre os métodos, entre as vias de acesso a esses domínios.

[1] Alternámos os grupos experimental e de controlo para que a possível influência de estágios anteriores fosse a mesma nos dois grupos. Com efeito, podemos supor que os aprendizes do $7 .^{\circ}$ grupo, que efectuaram o seu estágio no final do mês de Novembro (depois de terem feito a rectificação e o torneamento), podem obter melhores resultados do que os do 1. grupo que fazem o estágio logo em Outubro. 
[2] B.I.N.O.P., n. 91 de 1954 e n. ${ }^{\circ} 3$ de 1955.

[3] J. Levine : Aspects élémentaires de l'assimilation d'un enseignement vital. Enfance, 1955, p. 8, 119-167.

\section{NOTAS}

1. Alternámos os grupos experimental e de controlo para que a possível influência de estágios anteriores fosse a mesma nos dois grupos. Com efeito, podemos supor que os aprendizes do 7.․․ grupo, que efectuaram o seu estágio no final do mês de Novembro (depois de terem feito a rectificação e o torneamento), podem obter melhores resultados do que os do $1 .^{\circ}$ grupo que fazem o estágio logo em Outubro.

2. B.I.N.O.P., n. .01 de 1954 e n. .03 de 1955.

3. J. Levine: Aspects élémentaires de l'assimilation d'un enseignement vital. Enfance, 1955, p. 8, 119-167.

\section{RESUMOS}

Todo o erro profissional tem ao mesmo tempo um aspecto negativo e outro positivo. No seu trabalho, o indivíduo substitui uma resposta inadequada pela resposta correcta. É esta observação psicopedagógica corrente que é alvo de uma análise dedicada ao comportamento dos aprendizes fresadores. Expõe-se sucessivamente o método de observação e de controlo, e, de seguida, os resultados que evidenciam a importância dos fenómenos de generalização na génese dos erros profissionais.

Toda falta profesional comporta a la vez un aspecto negativo y otro positivo ya que el individuo ha sustituido en su trabajo la respuesta correcta por la respuesta inadecuada. Esta observación psicopedagógica corriente es objeto de un análisis consagrado al comportamiento en su oficio de los aprendices de fresador (máquinas de fresar). Sucesivamente se expone el método de observación y de control y luego los resultados que ponen al descubierto la importancia del fenómeno de generalización en la génesis de las faltas profesionales.

Analyse de quelques mécanismes d'acquisition des premiers éléments d'un métier chez l'adolescent

Toute faute professionnelle comporte à la fois un aspect négatif et un autre positif, l'individu substituant dans son travail une réponse inadéquate à la réponse correcte. C'est cette observation psychopédagogique courant qui fait l'objet d'une analyse, consacrée au comportement des apprentis fraiseurs. On expose successivement la méthode d'observation et de contrôle, puis les résultats qui mettent en lumière l'importance du phénomène de généralisation dans la genèse des fautes professionnelles. 
Every professional fault includes at one and the same time a positive and negative aspect, for the reason that in his work the individual substitutes an inadequate response for the correct one. This current psychopedagogic observation forms the subject of an analysis devoted to the behavior of the apprentices working milling machines. The method of observation and checking in first set forth and then the results which throw light on the importance of the phenomenum of generalization in the origin of professional faults.

\section{AUTOR}

\section{ANTOINE LÉON}

Service de Recherche de l'Institut National d'Etude du Travail et d'Orientation Professionnelle (INETOP) 